\title{
REVIEW
}

\section{Surgical treatment of male infertility in the era of intracytoplasmic sperm injection - new insights}

\author{
Sandro C. Esteves,' Ricardo Miyaoka,' Ashok Agarwal" \\ 'ANDROFERT - Andrology \& Human Reproduction Clinic, Campinas, São Paulo, Brazil. "Center for Reproductive Medicine, The Cleveland Clinic \\ Foundation, Cleveland, Ohio, USA.
}

\begin{abstract}
Assisted reproductive technology is an evolving area, and several adjuvant procedures have been created to increase a couple's chance of conceiving. For male infertility, the current challenges are to properly accommodate old and new techniques that are both cost-effective and evidence-based. In this context, urologists are expected to diagnose, counsel, provide medical or surgical treatment whenever possible and/or correctly refer male patients for assisted conception. Urologists are sometimes part of a multiprofessional team in an assisted reproduction unit and are responsible for the above-cited tasks as well as the surgical retrieval of sperm from either the epididymides or testicles. We present a comprehensive review of the surgical treatment options for infertile males, including the perioperative planning and prognostic aspects, with an emphasis on the role of microsurgery in the optimization of treatment results. This review also discusses current techniques for sperm retrieval that are used in association with assisted reproductive technology and includes sperm retrieval success rates according to the technique and the type of azoospermia. New insights are provided with regard to each surgical treatment option in view of the availability of assisted conception to overcome male infertility.
\end{abstract}

KEYWORDS: Male; Infertility; Surgery; Sperm retrieval; Review.

Esteves SC, Miyaoka R, Agarwal A. Surgical treatment of male infertility in the era of intracytoplasmic sperm injection - new insights. Clinics. 2011;66(8):1463-1477.

Received for publication on April 9, 2011; First review completed on April 15, 2011; Accepted for publication on April 19, 2011

E-mail: s.esteves@androfert.com.br

Tel.: 5519 3295-8877

\section{INTRODUCTION}

Infertility is a common complaint at urologists' offices and affects approximately $8 \%$ of reproductive-age men. Among these men, $1-10 \%$ present with conditions that affect their reproductive potential. ${ }^{1}$ In a group of 2,875 infertile couples who attended the first author's tertiary center for male reproduction, conditions that could potentially be corrected with surgical procedures were identified in approximately one third of the male partners. Azoospermic males who were not candidates for surgery or who remained azoospermic after surgical reconstruction could benefit from sperm retrieval techniques and assisted conception. Thus, surgical management may be offered to more than $50 \%$ of the infertile male patient population.

Two major advances have occurred in the area of male infertility surgery. One was the development of microsurgery, which increased success rates for the reconstruction of the reproductive tract with minimal morbidity. The second major advancement was the development of intracytoplasmic sperm injection (ICSI) and the demonstration that spermatozoa retrieved from either the epididymis or the testis were capable of fertilizing an egg and leading to

Copyright (c) 2011 CLINICS - This is an Open Access article distributed under the terms of the Creative Commons Attribution Non-Commercial License (http:// creativecommons.org/licenses/by-nc/3.0/) which permits unrestricted noncommercial use, distribution, and reproduction in any medium, provided the original work is properly cited. pregnancy. ${ }^{2,3}$ Several sperm retrieval methods were developed to collect epididymal and testicular sperm for ICSI in azoospermic men. Microsurgery facilitated sperm collection from the epididymides in men with obstructive azoospermia (OA) and from the testicles in men with nonobstructive azoospermia (NOA). ${ }^{2,4}$ As for all surgical reconstructive procedures discussed in this chapter, an evaluation of the female partner's reproductive potential is recommended before an intervention is indicated, and options should be individually discussed with each couple.

\section{WHAT ARE THE AVAILABLE SURGICAL TREATMENTS?}

\section{Varicocele repair}

Varicocele can be diagnosed in up to $35 \%$ of infertile men. It is currently recommended that treatment should be offered to couples with documented infertility whose male partner has a clinically palpable varicocele associated with an abnormal semen analysis. The preferred diagnostic method is a physical examination with the patient standing in a warm room. ${ }^{5}$ In the case of bilateral palpable varicocele, studies have recommended that both sides be corrected during the same procedure. ${ }^{6}$ Imaging studies should be performed when physical examination is inconclusive. When a varicocele is not palpable but a retrograde blood flow is detected by other diagnostic methods (such as venography, Doppler examination, ultrasonography, scintigraphy or thermography), the varicocele is termed subclinical. ${ }^{7,8}$ Current evidence 
does not support treating infertile men who have subclinical varicocele. ${ }^{9,10}$

\section{Preoperative planning}

A preoperative hormone profile that includes an analysis of follicle-stimulating hormone (FSH) and testosterone, a testicular volume assessment using a measurement instrument such as the Prader orchidometer or a pachimeter, and the results of at least two semen analyses should be obtained. ${ }^{11}$ Men with clinical varicoceles presenting with azoospermia may be candidates for surgical repair, but genetic evaluation including Giemsa karyotyping and polymerase chain reaction screening for $\mathrm{Yq}$ microdeletion of the $\mathrm{AZFa}, \mathrm{AZFb}$, and $\mathrm{AZFC}$ regions is recommended. A testis biopsy (open or percutaneous) provides testicular histology, which has been shown to be the only significant prognostic factor for the restoration of spermatogenesis in azoospermic individuals with varicocele. $^{11,12}$ The benefit of varicocelectomy in azoospermic men with genetic abnormalities is doubtful and the procedure should be carefully considered. The same caution must be used for patients with atrophic testes and/or a history of cryptorchidism, testicular trauma, orchitis, or systemic or hormonal dysfunction; varicocele may be coincidental in these cases rather than the cause of infertility. ${ }^{13}$

\section{Operative aspects}

Varicocele repair may be carried out using local, regional, or general anesthesia (the choice is solely dependent on the surgeon's preferences). We perform varicocele repair on an outpatient basis using short-acting intravenous propofol anesthesia along with anesthesia of the spermatic cord using lidocaine hydrochloride. ${ }^{11}$ Varicocelectomy can be performed through either open (with or without magnification) or laparoscopic approaches. The main concern is the occlusion of the dilated veins of the pampiniform plexus.

The high retroperitoneal and laparoscopic approaches are used for internal spermatic vein ligation, whereas the inguinal and subinguinal approaches allow for the ligation of the internal and external spermatic and cremasteric veins that may contribute to the varicocele. High retroperitoneal open varicocele ligation is performed through an incision medial to the anterior superior iliac spine at the level of the internal inguinal ring. Exposure of the internal spermatic vessels is carried out retroperitoneally near the ureter. At this level, the internal spermatic artery may not be easy to identify. In addition, neither the parallel inguinal and retroperitoneal collateral veins that may bypass the retroperitoneal area of ligation nor the cremasteric veins can be identified. This may explain the high recurrence rate seen in retroperitoneal varicocelectomy. Laparoscopic varicocelectomy is similar to the retroperitoneal procedure, but it uses high magnification. The spermatic artery and the lymphatics are easily identified and spared. In addition, collateral veins can be clipped or coagulated. External spermatic veins, however, which are the second cause of varicocele recurrence, cannot be treated (this leads to a recurrence close to $5 \%) .{ }^{14}$ Laparoscopic varicocele repair is more invasive, costly and associated with higher complication rates compared with open procedures. ${ }^{14-16}$

The classical approach to the inguinal varicocelectomy involves an incision over the inguinal canal, opening of the external oblique aponeurosis and isolation of the spermatic cord. The internal spermatic veins are dissected and ligated. Testicular arteries and the lymphatics should be actively identified. External spermatic veins running parallel to the spermatic cord or perforating the floor of the inguinal canal can also be identified and ligated. The use of magnification facilitates the identification and preservation of internal spermatic arteries and lymphatics; the preservation of these structures may prevent testicular atrophy and hydrocele formation, respectively. ${ }^{17}$ Microsurgical varicocelectomy can be performed via an inguinal or subinguinal approach using a testicular artery and lymphatic-sparing subinguinal microsurgical repair (Figure 1). ${ }^{11,18}$ The latter offers the advantage of sparing the aponeurosis of the external oblique muscle, which may result in less postoperative pain and a shorter time before the patient can return to work. The operation is performed under the microscope with magnification ranging from 6-16X. All dilated veins of the spermatic cord are identified, tagged, and ligated.

\section{Postoperative care}

Local dressing and scrotal support are maintained for 48$72 \mathrm{~h}$ and one week, respectively. Scrotal ice packing is always recommended to control local edema for the first 48 h. Patients are counseled to refrain from physical activity and sexual intercourse for 2-3 weeks. Oral analgesics usually suffice to control postoperative pain. Follow-up aims to evaluate improvement in semen parameters, complications and spontaneous or assisted conception. Semen analysis should be performed every three months until the semen parameters stabilize or pregnancy occurs.

\section{RECONSTRUCTIVE SURGERY OF THE VAS DEFERENS AND EPIDIDYMIS}

Vasovasostomy (VV) and vasoepididymostomy (VE) are designed to bypass an obstruction in the male genital tract. The number of men seeking vasectomy reversal due to changes in marital status or reproductive goals has increased and varies from 2-6\%. ${ }^{19}$ In Brazil, it is estimated that 200,000 vasectomies and 7,000 reversals are performed each year. ${ }^{20}$ In addition to vasectomy, epididymal or vasal obstructions may be secondary to genital infections or iatrogenic injuries related to inguinal or scrotal surgery (especially during the early childhood years). ${ }^{21}$

\section{Preoperative planning}

A detailed medical history must be taken, and prognostic factors should be identified. Obstruction intervals after vasectomy play a major role in determining surgical outcomes. Vasoepididymostomy is more likely to be required after long-interval obstructions because they are associated with a higher incidence of epididymal obstruction. A computer model based on obstructive interval and patient age was created to determine the need for VE. ${ }^{22}$ Free shareware versions are available at www.uroengineering. com.

A history of a previous vasectomy reversal attempt does not preclude a new attempt. Patency and pregnancy rates of $79 \%$ and $31 \%$, respectively, have been reported for repeated reversals. ${ }^{23}$ Small and soft testes may indicate impaired spermatogenesis. Indurate, irregular epididymides, and the presence of hydrocele are often associated with epididymal obstruction and may indicate the need for VE. The presence of a granuloma in the vas deferens should be interpreted as a favorable prognostic sign because this means that sperm have leaked from the vasectomy site (i.e., this prevents too much 


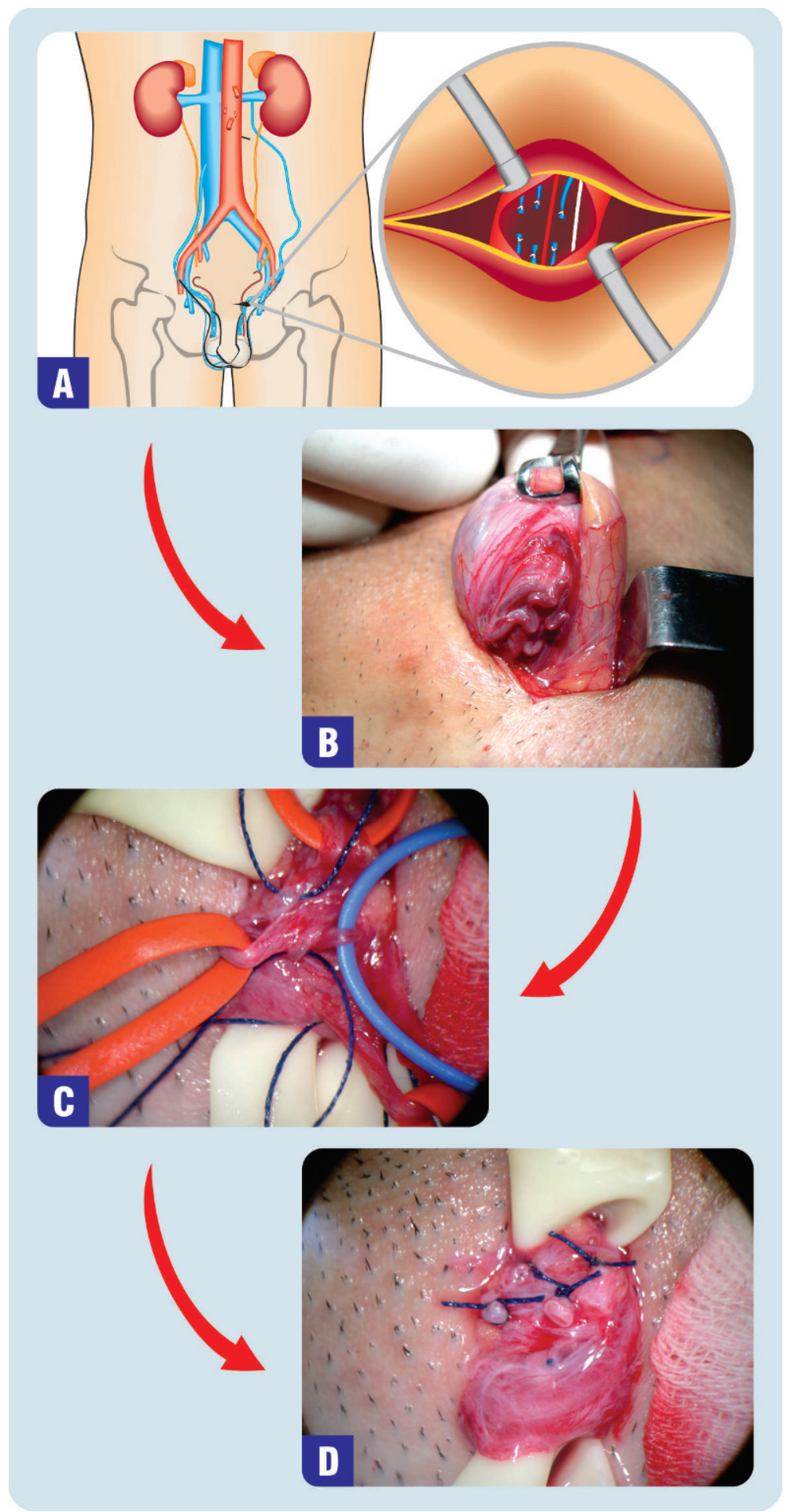

Figure 1 - Microsurgical Subinguinal Varicocele Repair. A) A transverse incision is made just below the level of the external inguinal ring. B-D) Intraoperative photographs of the spermatic cord. B) Dilated cremasteric veins are identified by elevating the spermatic cord with a Babcock clamp. C) Testicular artery (blue vessel loop), lymphatics (blue cotton suture), and dilated varicose veins (red vessel loops) are demonstrated. D) Final surgical aspects of the varicose veins are transected and ligated with nonabsorbable sutures.

pressure from building up within the epididymides tubules, which can lead to rupture).$^{19,24,25}$ Specific laboratory tests are not necessary before reconstructive surgeries. Serum FSH is only recommended as a marker of testicular reserve if testicular damage is suspected on physical examination. The usefulness of antibody testing remains controversial, and evidence suggests that late failures following reversals are likely to be technical rather than immunological. ${ }^{25,26}$

\section{Operative Aspects}

Vasovasostomy and vasoepididymostomy may be performed using local, regional, or general anesthesia. We 
perform VV and VE on an outpatient basis using continuous intravenous propofol anesthesia along with spermatic cord anesthesia with a lidocaine hydrochloride solution. A longitudinal scrotal incision is made in the anterior aspect of the scrotum on each side. The incision is made onto the palpable granuloma or onto the identified vasal gap, and only the vas ends are delivered through the skin incision. In cases where the vasectomy was performed high in the scrotum or a large segment was removed or repeat reconstructions were performed with difficult vasal mobilization, the incision may be extended to the inguinal region. Microsurgical dissection is carried out in the region of the prior vasectomy site to free the vas and its vascular pedicle from the surrounding scar tissue. Hemostasis is obtained with great care using either bipolar or hand-held thermal cautery units. After the vas has been mobilized and its scarred ends excised, patency of the abdominal vas end is confirmed with the introduction of a 24-gauge blunt tipped angiocatheter into the lumen and the injection of sterile saline. Fluid from the testicular vas end is examined for the presence of sperm. Copious, clear, watery or cloudy fluid and motile sperm has been shown to be associated with an excellent patency rate of $94 \%$, which is compared with $60 \%$ when no sperm is found in the vasal fluid. ${ }^{19}$ Thick, toothpaste-like vasal fluid is suggestive of epididymal obstruction. ${ }^{19,27}$ The most important factors in determining the type of reconstructive technique are the quality of sperm found in the intravasal fluid and the surgeon's microsurgical skills. Indeed, attention to surgical details directly affects the success of reconstructive microsurgeries. Important surgical details include the accurate mucosa-to-mucosa approximation, a water-tight tension-free anastomosis, preservation of the vasal blood supply and healthy tissue (mucosa and muscularis), and an adequate microscopic atraumatic technique.

Several techniques have been described for VV: (i) the modified one-layer technique, which has been described by Sharlip, ${ }^{28}$ (ii) the two-layer technique, which has been described by Belker, ${ }^{29}$ and (iii) the multilayer microdot technique, which was originally described by Goldstein. ${ }^{30}$ Recent reports have shown that it is possible to perform classical techniques using robotic assistance. Robots can offer the benefits of enhanced imaging (up to 100X magnification) and control of tremor. ${ }^{31,32}$

Vasoepididymostomy is a challenging surgical procedure that should only be attempted by experienced microsurgeons. Meticulous microsurgical technique and high magnification are required for a precise anastomosis of the vas (luminal diameter of $300-400 \mu \mathrm{m}$ ) to the epididymal tubule (150-250 $\mu \mathrm{m})$. Intraoperative sperm harvesting and cryopreservation can be offered during VE. ${ }^{33}$ The VE procedure starts with the placement of a longitudinal incision in the upper scrotum. The testis is delivered, and the testis and epididymis are thoroughly inspected. The site of obstruction can often be grossly visible as an area where the epididymis transitions from a firm, wide caliber to a smaller, softer structure. The distal end of the vas deferens is mobilized in a similar fashion to the VV procedure, but a longer length is generally required to perform an epididymal anastomosis. Anastomosis is performed under an operating microscope. Currently, three variations of the technique have been used for precise approximation of the vas deferens lumen to a single epididymal tubule: end-to-end, end-to-side, and endto-side intussusception techniques (Figure 2). ${ }^{34,35}$ Prior to the anastomosis, a dilated epididymal tubule must be identified immediately above the level of obstruction. The tubule must be opened, and the fluid should be inspected for the presence of motile sperm. If no sperm are identified, a more proximal site of the epididymis will be required for the anastomosis.

Microsurgical techniques are clearly superior than macrosurgical or loupe-assisted anastomoses. ${ }^{19,36}$ The likelihood of sperm appearance in the semen and of pregnancy after microsurgical vasectomy reversal are inversely related to the duration of time since the vasectomy. ${ }^{19}$ Other factors that are related to success rates include the gross appearance of vas fluid at the time of surgery, the presence or absence of sperm in the vas fluid (and sperm quality), the length of the remaining segment adjacent to the epididymis, the age of the female partner, and the experience of the microsurgeon.

\section{Postoperative care}

Local dressing and ice packing are maintained for 48$72 \mathrm{~h}$, and a scrotal supporter should be used for two weeks. Patients are counseled to restrain from physical activity and sexual intercourse for one and two months in cases of VV and VE, respectively. Oral analgesics usually suffice to control postoperative pain. Postoperative follow-up should evaluate improvement in semen parameters, complications and spontaneous or assisted conception. Semen analysis should be performed every two months after surgery until the semen parameters stabilize or pregnancy occurs.

\section{TRANSURETHRAL RESECTION OF THE EJACULATORY DUCT (TURED)}

Ejaculatory duct obstruction (EDO) is a cause of male infertility that can potentially be corrected by surgery. Congenital obstructions are caused by atresia or stenosis of the ejaculatory ducts as well as utricular, mullerian, and wolffian duct cysts. Acquired obstructions may be secondary to trauma or infection/inflammation. Traumatic damage to the ejaculatory ducts may occur after the removal of seminal vesicle cysts, pull-through operations for an imperforate anus or even prolonged urethral catheterization or instrumentation. Genital or urinary infection and prostatic abscess may cause stenosis or complete obstruction of the ducts. ${ }^{37}$

\section{Preoperative planning}

Diagnostic assessment should include history, physical examination, semen analyses, and transrectal ultrasound. The clinical presentation may be highly variable. Indeed, in addition to a history of infertility, complaints may include painful ejaculation, hemospermia, and perineal and/or testicular pain; however, some patients may be completely asymptomatic. Unaltered physical examination is the rule. Occasionally, the seminal vesicles or a mass are palpable on rectal examination. Prostatic tenderness and/or epididymal enlargement may also exist. Hormone profiles are generally normal. Semen analyses may reveal oligozoospermia or azoospermia, decreased motility, and decreased ejaculate volume. The presence of a low volume $(<1.5 \mathrm{~mL})$ of acidic $(\mathrm{pH}<7.0)$ azoospermic ejaculate with absent fructose, palpable vasa, and epididymal thickening is virtually pathognomonic. The typical clinical picture, however, may be complicated because obstruction could be unilateral, partial, or functional. ${ }^{37}$ Postejaculate urinalyses are often performed 


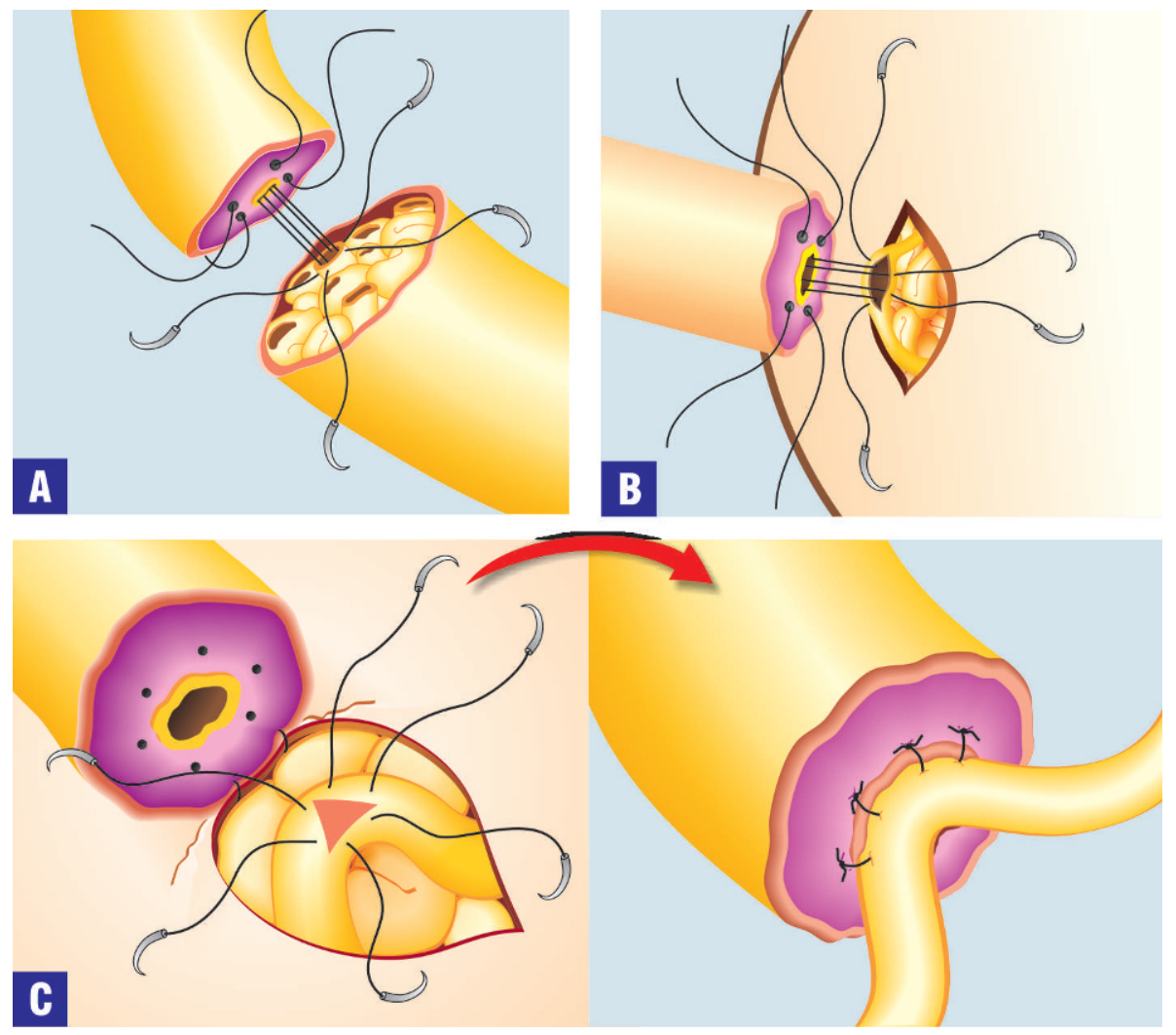

Figure 2 - Microsurgical Vasoepididymostomy Techniques. A) Illustration of the end-to-end, B) end-to-side, and C) triangulation end-toside anastomoses.

to exclude retrograde ejaculation in patients with lowvolume ejaculates. High-resolution transrectal ultrasound evaluation (TRUS) using with a 5-7 MHz biplanar transducer is recommended in all cases of suspected EDO. The precise identification of obstruction on TRUS, however, is still a matter of debate because of marked variability in the size and shape of the vas deferens, seminal vesicles, and ejaculatory ducts in both fertile and infertile men. Common ultrasound findings include dilation of the seminal vesicles (defined as a cross-sectional width greater than $1.5 \mathrm{~cm}$ ) or ejaculatory ducts (defined as an internal duct diameter greater than $2.0 \mathrm{~mm}$ ), calcifications or calculi in the region of the ejaculatory duct or verumontanum and midline or eccentrically located prostatic cysts. ${ }^{38-40}$ Ultrasound-guided transrectal seminal vesiculography has been shown to provide excellent radiographic visualization of the ejaculatory ducts. ${ }^{41}$ In addition, TRUS-guided seminal vesicle aspiration revealing the presence of motile sperm in the aspirates seem to be an useful diagnostic tool because the seminal vesicles are not sperm reservoirs. ${ }^{42}$ Moreover, a testicular biopsy can be performed to document the presence of normal spermatogenesis. Our preference is to perform a "wet prep" using the percutaneous testicular sperm aspiration technique either before or at the time of surgery; the presence of motile sperm is highly indicative of ductal obstruction.

\section{Operative aspects}

Transurethral resection of the ejaculatory ducts (TURED) is performed using regional or general anesthesia according to the procedure that was originally described by Farley and Barnes, ${ }^{43}$ with minor modifications. ${ }^{37}$ The obstruction is initially documented using intraoperative vasotomy and vasography. The vas is delivered using a small scrotal incision and dissected free of the associated perivasal vessels. A mixture of injectable saline, radiographic contrast material, and methylene blue dye is injected into the abdominal end of the vas by direct vas puncture with a 30-gauge lymphangiogram needle. ${ }^{37}$ Vasography is used to confirm the obstruction, and dye injection is used to confirm patency by visualization of the effluxing dye mixture during TURED. A suture is placed at the muscular layer of the vas to close the vasotomy site. Transurethral resection of the ejaculatory ducts is performed with the patient in the dorsal lithotomy position. A strip of tissue is removed from the floor of the prostate just proximal to and including a portion of the verumontanum. The ducts are confirmed to be properly opened by visualizing their dilated portion and the dye efflux.

\section{Postoperative care}

An indwelling catheter is kept in place for $24-48 \mathrm{~h}$, and patients are discharged the following day. Oral quinolone antibiotics and anti-inflammatory medication are prescribed for five days. In addition, scrotal support is recommended for one week to avoid vasotomy-induced scrotal edema. Frequent ejaculation is recommended 3-4 weeks postoperatively, and patients are monitored with monthly semen analyses.

\section{WHAT ARE THE AVAILABLE SPERM RETRIEVAL TECHNIQUES?}

Azoospermia, which is defined as the absence of spermatozoa in the ejaculate after centrifugation, is found in $1-3 \%$ of 
the male population and approximately $10 \%$ of infertile males. ${ }^{42}$ In obstructive azoospermia (OA), spermatogenesis is normal, but a mechanical blockage in the genital tract, somewhere between the epididymis and the ejaculatory duct, or the absence of the epididymis and vas deferens prevents spermatozoa from being expelled in semen. Acquired OA may be secondary to vasectomy or result from a failed vasectomy reversal, postinfectious diseases, surgical procedures in the scrotal, inguinal, pelvic or abdominal regions, or trauma. Congenital causes of OA include cystic fibrosis, congenital absence of the vas deferens (CAVD), ejaculatory duct or prostatic cysts, and Young's syndrome. ${ }^{42}$ Nonobstructive azoospermia (NOA) comprises a spectrum of testicular histopathology resulting from various causes, such as environmental toxins, medications, cryptorchidism, genetic and congenital abnormalities, varicocele, trauma, viral orchitis, endocrine disorders, or idiopathic causes. In both OA and NOA, pregnancy may be achieved through in vitro fertilization (IVF) associated with ICSI. ${ }^{2,3}$

Several surgical methods have been developed to retrieve epididymal and testicular sperm from azoospermic men. Either percutaneous epididymal sperm aspiration (PESA) ${ }^{44}$ or microsurgical epididymal sperm aspiration (MESA) ${ }^{2}$ can be successfully used to retrieve sperm from the epididymides in men with obstructive azoospermia. In addition, testicular sperm aspiration (TESA) can be used to retrieve sperm from the testes in men with OA who fail PESA and in men with NOA. ${ }^{44}$ Moreover, testicular sperm extraction (TESE) using single or multiple open biopsies ${ }^{45,46}$ and, more recently, microsurgery (micro-TESE) are indicated for men with NOA., ${ }^{46-49}$ The goals of surgical sperm retrieval are (i) to retrieve an adequate number of sperm for both immediate use and for cryopreservation, (ii) to obtain the best quality sperm possible, and (iii) to minimize damage to the reproductive tract to avoid jeopardizing future sperm retrieval attempts or testicular function. Sperm can be easily obtained from infertile men with OA, whereas individuals exhibiting NOA have historically been the most difficult to treat.

\section{Preoperative Planning}

It is important to distinguish whether the lack of sperm in the ejaculate is from an obstructive or nonobstructive cause because the choice of the retrieval method is based on the type of azoospermia. History, physical examination, and hormonal analysis (FSH and testosterone) provide about a $90 \%$ ability to predict whether the cause is obstructive or nonobstructive. ${ }^{50}$ Men with OA usually have normal testes and a normal hormone profile. Occasionally, the epididymides or the seminal vesicles may be enlarged or a cyst may be palpable on rectal examination. The presence of a low volume $(<1.5 \mathrm{ml})$ of acidic $(\mathrm{pH}<7.0)$ azoospermic ejaculate with absent or low fructose and epididymal thickening is pathognomonic of $\mathrm{OA}$ due to either congenital bilateral absence of the vas deferens or EDO (the differential diagnosis would be the presence of the vas in the latter). Approximately two thirds of men with CAVD have mutations of the cystic fibrosis transmembrane conductance regulator (CFTR) gene. Failure to identify a CFTR abnormality in a man with CAVD does not rule out the presence of a mutation because some mutations are undetectable by routine testing methods. The female partner should be offered cystic fibrosis (CF) testing before proceeding with treatments that utilize the sperm from men with CAVD because of the high risk of the male being a CF carrier. If a
CFTR gene mutation is identified (approximately $4 \%$ of female partners are carriers), testing should also be offered to the male, and counseling is recommended before proceeding with sperm retrieval and ICSI because of the risk of the transmission of cystic fibrosis to the offspring. ${ }^{51,52}$ Azoospermic men with idiopathic obstruction and men with a clinical triad of chronic sinusitis, bronchiectasis, and obstructive azoospermia (Young's syndrome) may also be at higher risk for CF gene mutations.

Serum FSH is a critical factor in determining whether a diagnostic testicular biopsy is needed to differentiate the type of azoospermia in men with normal semen volume. Elevated FSH and small testicles are indicative of testicular failure (i.e., NOA); therefore, a testicular biopsy is not necessary for diagnostic purposes. ${ }^{51}$ If sperm retrieval with ICSI is being considered, however, a biopsy may be performed for prognostic purposes because histology correlates with the odds of finding sperm by aspiration or dissection. The absence of sperm in a biopsy specimen taken from a man with NOA, however, does not absolutely predict whether sperm are present elsewhere within the testicle. ${ }^{4,52}$ Conversely, men with normal levels of FSH and semen volume may have either NOA or OA. ${ }^{53}$ In such cases, no noninvasive method can differentiate between the two forms, and a testicular biopsy is usually required to provide a definitive diagnosis. Testicular biopsy can be performed by a standard open-incision technique or by percutaneous methods. Histological evaluation of testicular specimens may indicate the presence of normal spermatogenesis in cases of OA, whereas hypospermatogenesis (HS), maturation arrest (MA), or Sertoli-cell-only (SCO) syndrome are seen in cases of NOA.

All men with primary testicular failure of unknown origin should be offered karyotyping and $\mathrm{Yq}$ microdeletion testing. The frequency of karyotypic abnormalities is reported to be $10-15 \%$ in men with NOA, and Klinefelter syndrome accounts for approximately two-thirds of cases. ${ }^{54}$ Genetic testing may provide prognostic information for sperm retrieval. ${ }^{50}$ While sperm can be found within the testes of approximately $70 \%$ of patients with partial or complete AZFc deletion, it is unlikely that sperm will be found in men with complete AZFa or AZFb deletions. ${ }^{55,56}$ Genetic counseling should be offered whenever a genetic abnormality is detected in the male prior to performing ICSI with his sperm.

Sperm retrieval from the epididymis is only indicated in obstructive cases. Testicular sperm retrieval can be performed in either OA or NOA cases. In OA, testicular retrievals are carried out after failed epididymal retrieval or as a primary retrieval procedure in cases of absent epididymis or intense epididymal fibrosis. In NOA, testicular sperm retrievals are the only option for the collection of sperm.

\section{Operative aspects}

Sperm retrieval techniques may be performed using local, regional, or general anesthesia. Percutaneous sperm retrievals by needle aspiration are easily repeatable and less expensive than open macro- or microsurgical techniques. Moreover, the procedures do not require microsurgery training and causes less postoperative pain. Microsurgical techniques, however, are associated with better quality and higher numbers of sperm retrieved per attempt, which 
optimize the opportunity to cryopreserve sperm for future ICSI procedures.

Typically, PESA is performed on an outpatient basis using a needle attached to a syringe. The main goal is to aspirate epididymal fluid for diagnostic or therapeutic purposes. Loupe magnification may be used to avoid injuring small vessels in the scrotal skin. Negative pressure is created, and the tip of the needle is gently moved in and out of the epididymis until fluid enters the syringe. The amount of epididymal fluid obtained during aspiration is often minimal $(\sim 0.1 \mathrm{~mL})$, except in cases of CAVD, when 0.3 $1.0 \mathrm{ml}$ may be aspirated. After the needle is withdrawn from the epididymis, the aspirate is flushed into sperm medium. The tube containing the epididymal aspirate is transferred to the laboratory for microscopic examination. PESA is repeated at a different site of the same epididymis (from the cauda up to the caput) and/or at the contralateral epididymis until an adequate number of motile sperm are retrieved. If PESA fails to retrieve motile sperm for ICSI, TESA is performed at the same operative time. For TESA, the epididymis is stabilized between the index finger, thumb, and forefinger while the anterior scrotal skin is stretched. A needle is inserted through the stretched scrotal skin into the anteromedial or anterolateral portion of the superior testicular pole in an oblique angle towards the medium and lower poles. When a small piece of testicular tissue is aspirated, the needle is gently withdrawn from the testis while the negative pressure is maintained. The specimen is flushed into a tube containing $0.5-1.0 \mathrm{ml}$ warm sperm medium and transferred to the laboratory for microscopic examination. TESA or TESE may be performed at the contralateral testis if insufficient or no sperm are obtained.

Microsurgical sperm retrieval allows direct visualization of epididymal and seminiferous tubules with high magnification. These techniques have been associated with the retrieval of higher sperm numbers and better quality sperm in MESA and higher retrieval success rates in micro-TESE. Importantly, MESA does not compromise the success of future reconstructive procedures because the damage to the epididymal tubule is minimal. In addition, sperm cryopreservation is feasible in most MESA cases. In MESA, fluid exuding from the tubule is aspirated with a silicone tube or blunted needle attached to a 1-ml tuberculin syringe (Figure 3). The aspirate is flushed into $0.5-1.0 \mathrm{ml}$ of sperm medium at $37^{\circ} \mathrm{C}$, and the tube containing the epididymal aspirate is transferred to the laboratory for microscopic examination. MESA is repeated at a different site of the same epididymis (from the cauda up to the caput) and/or at the contralateral epididymis until an adequate number of motile sperm are retrieved. If MESA fails to retrieve motile sperm, TESA or TESE may be performed at the same operative time. For testicular sperm extraction (micro-TESE), a single large, mid-portion incision is made in the tunica albuginea to expose the testicular parenchyma (Figure 3). Dissection of the testicular parenchyma is carried out at 16-25X magnification, and the surgeon should search for enlarged seminiferous tubules. The superficial and deep testicular regions may be examined if necessary, and microsurgical-guided testicular biopsies are performed by removing enlarged tubules, which are more likely to harbor active spermatogenesis (Figure 3). If enlarged tubules are not observed, then any tubule that is a different size than the rest of the tubules should be excised. If all tubules are identical in appearance, random microbiopsies (at least three at each testicular pole) are performed. Testicular tissue specimens are placed in an outerwell dish containing sperm media. Specimens are washed grossly to remove blood clots, and they are sent to the laboratory for processing and to search for sperm. The albuginea and scrotal layers are closed using nonabsorbable and absorbable sutures, respectively. Conventional TESE, using single or multiple open biopsies, can also be used to obtain sperm in cases of both OA and NOA, but TESE is primarily used in cases of NOA. TESE can also be used as a diagnostic tool to obtain testicular parenchyma for histological analysis and to search for sperm prior to the ICSI cycle. Conventional TESE is carried out without magnification. A small self-retaining eyelid retractor is used to improve exposure of the tunica albuginea and facilitate incision. Gentle pressure is applied to the testis to extrude testicular parenchyma out of the small incision and assist in its removal. TESE can be repeated in a different testicular pole if the multiple biopsies approach is selected. The amount of testicular parenchyma removed in micro-TESE is low compared with conventional TESE; this low removal is particularly important because it helps preserve testicular androgen production in men with NOA who already have compromised testes.

\section{Postoperative care}

Patients are discharged on the same day and can return to normal activities one and three days after percutaneous and open techniques, respectively. Scrotal ice packing and support is recommended to control edema and alleviate pain. Patients should refrain from ejaculation and strenuous physical activity for approximately 7-10 days. In addition, oral analgesics are generally prescribed.

\section{NEW INSIGHTS INTO THE SURGICAL TREATMENT OF MALE INFERTILITY}

\section{Varicocele Repair}

In a recent systematic review comparing surgical modalities used to treat varicocele, ${ }^{14}$ open microsurgical inguinal or subinguinal varicocelectomy techniques resulted in higher spontaneous pregnancy rates and fewer recurrences and postoperative complications than laparoscopic, radiologic embolization, and macroscopic inguinal or retroperitoneal techniques. A study by Cayan showed that hydrocele formation was the most common complication of varicocelectomy, and the incidence ranged from 0-10\%. Recurrences were reported in the range of $0 \%-35 \%$. Overall recurrence rates were lower for microsurgical varicocelectomy and higher for retroperitoneal and macrosurgical inguinal approaches. ${ }^{14}$ The rate of accidental testicular artery ligation during microsurgical varicocelectomy has been reported to be about $1 \%$, and this may cause testicular atrophy (Table 1 ). Recently, a study demonstrated that the concomitant use of intraoperative vascular Doppler monitoring during microsurgical varicocelectomy allows for more arterial branches to be preserved, and more internal spermatic veins are likely to be ligated. ${ }^{57}$

Varicocelectomy studies have reported significant improvements in one or more semen parameters in approximately $65 \%$ of men. ${ }^{58}$ Higher preoperative semen parameters or varicocele repair for large varicoceles are more likely to show postoperative improvements in semen parameters. ${ }^{58,59}$ The mean time for semen improvement and spontaneous pregnancy after surgery is approximately five and seven 


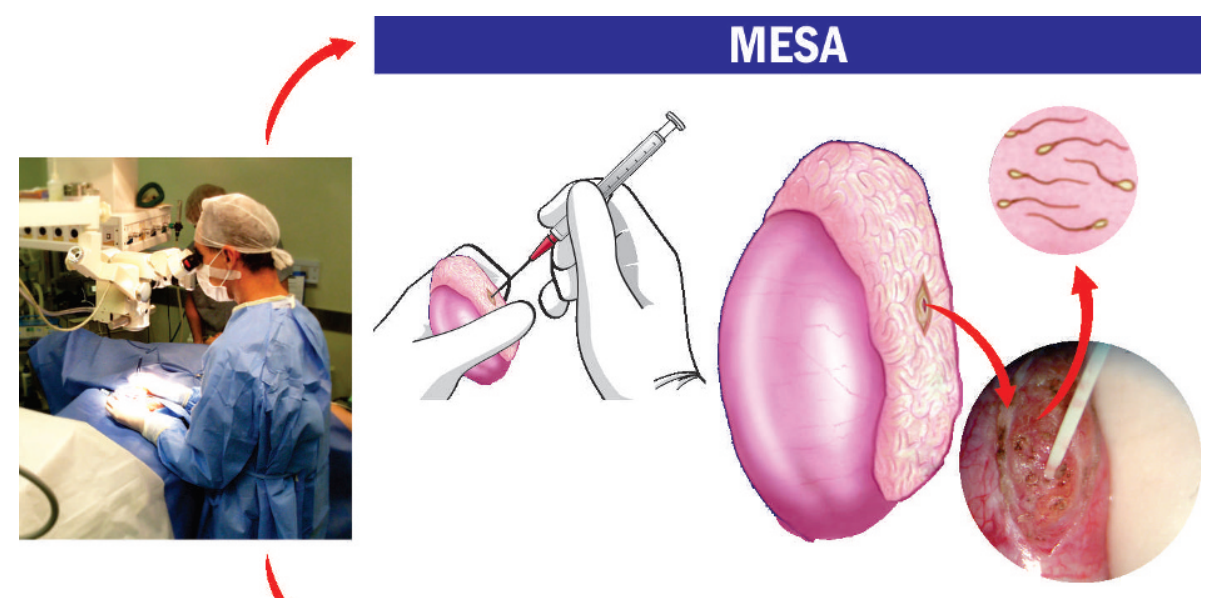

micro-TESE

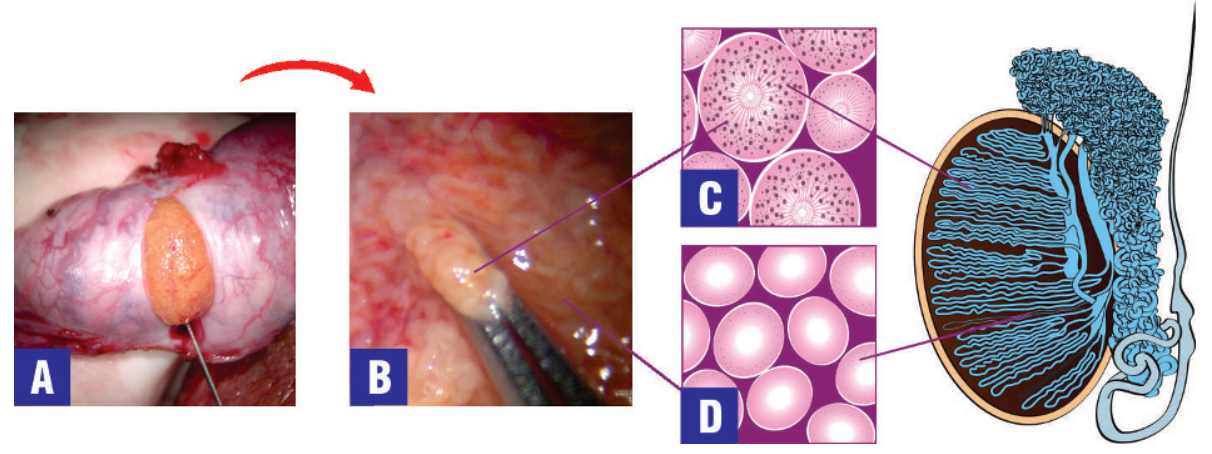

Figure 3 - Microsurgical Sperm Retrieval Techniques. Operating microscope and microsurgical techniques are used throughout the procedures. The top image shows microsurgical epididymal sperm aspiration (MESA). After exposure of the testis and epididymis, a dilated epididymal tubule is dissected and opened. Fluid is aspirated, diluted with sperm medium and sent to the laboratory for examination. The bottom images show microsurgical testicular sperm extraction (micro-TESE). A) After the testicle is exteriorized, a single and large incision is made in an avascular area of the albuginea to expose the seminiferous tubules. B) Dilated tubules are identified and removed with microforceps (intraoperative photograph at 40X magnification). C) Illustration of the histopathology cross-section of a dilated seminiferous tubule with active spermatogenesis. D) Illustration of the histopathology cross-section of a thin tubule with Sertoli-cell-only syndrome.

months, respectively. ${ }^{60}$ Studies have also reported that the surgical treatment of clinical varicoceles is highly effective in decreasing seminal oxidative stress and increasing seminal concentrations of antioxidants. ${ }^{61,62}$ Conversely, reduced preoperative testicular volume, elevated serum FSH levels, diminished testosterone concentrations, subclinical varicocele, and the presence of $Y$ chromosome microdeletions seem to be negative predictors for fertility improvement after surgery. ${ }^{63,64}$ The management of infertility in men with a unilateral clinical varicocele and a subclinical varicocele on the contralateral side is a matter of debate. For example, Zheng et al. found that bilateral varicocelectomy had no benefit over left clinical varicocelectomy. ${ }^{65}$ Elbendary et al., however, observed that the magnitude of change in sperm count and motility and the spontaneous pregnancy rates were significantly higher in the group of men who had bilateral varicocele repair. $^{66}$

Several guidelines propose that varicoceles should be treated if palpable and if abnormal semen analyses are observed. ${ }^{67-69}$ A recent meta-analysis of varicocelectomy conducted by Marmar et al. (2007) demonstrated the benefit of the surgical treatment of clinical varicoceles in infertile men with abnormal semen analyses. ${ }^{70}$ The authors showed that the chances of spontaneous conception were 2.8-times

Table 1 - Treatment Results for Varicocele Repair in Infertile Men. Postoperative Recurrence, Hydrocele Formation and Spontaneous Pregnancy Rates using Various Techniques*.

\begin{tabular}{|c|c|c|c|}
\hline Technique & Recurrence Rate & Hydrocele Formation Rate & Spontaneous Pregnancy Rate \\
\hline Retroperitoneal High-Ligation ${ }^{14,16}$ & $7-35 \%$ & $6-10 \%$ & $25-55 \%$ \\
\hline Laparoscopic $^{14,16}$ & $2-7 \%$ & $0-9 \%$ & $14-42 \%$ \\
\hline Macroscopic Inguinal ${ }^{14,16}$ & $0-37 \%$ & $7 \%$ & $34-39 \%$ \\
\hline Microscopic Inguinal or Subinguinal $6,14,16,59$ & $0-0.3 \%$ & $0-1.6 \%$ & $33-56 \%$ \\
\hline
\end{tabular}

*Values are expressed as ranges. 
higher in the varicocelectomy group compared with the group of patients who either did not receive treatment or received medication.

Interestingly, the reference values for semen parameters normalcy are lower in the newly released edition of the World Health Organization (WHO) manual for examination of human sperm than in previous editions. ${ }^{71-74}$ According to these new reference values, several patients with clinical varicoceles who had been previously categorized as having abnormal semen parameters would be reclassified as having normal semen and would not be eligible for treatment under the current guidelines for varicocele treatment. The question is not simply whether a man should undergo repair of clinical varicoceles if he has normal semen variables. Indeed, what we are really interested in determining is what the semen parameters of the same individual would have been if varicocele had been treated. It would be very informative to reanalyze the meta-analysis studies of varicocelectomy to determine the magnitude of sperm quality improvement in the subgroup of patients that is now classified as having 'normal' semen. This information will certainly come, but emerging evidence seems to indicate the benefits of treatment for men with clinical varicocele and so-called 'normal' semen parameters according to the new WHO reference values. In one study, Agarwal et al. examined the effect of varicocelectomy on the semen parameters of adults and demonstrated a significant increase in sperm concentration, motility and morphology by 9.7 million $/ \mathrm{ml}, 9.9 \%$, and $3.1 \%$, respectively. ${ }^{75}$ In another study, Mori et al. examined a group of 360 nonselected adolescents between the ages of 14-18 years who attended a public school in Brazil. ${ }^{76}$ They found that $27.8 \%$ presented a palpable grade II or III varicocele, but only half of the adolescents had testicular asymmetry. More importantly, semen analysis results revealed that adolescents without varicocele ejaculated a significantly higher number of progressively motile sperm (134.1 million) compared with adolescents with grade II (72.7 million) or grade III (30.3 million) varicocele. Despite the marked difference in the seminal profile between adolescents with and without varicocele, all individuals were still within the reference range for normality according to the latest editions of the WHO manual. Because these semen samples are still considered normal, and because testicular asymmetry will not be detected in $\geq 50 \%$ of adolescents, treatment would not be recommended according to the published guidelines of current professional societies, such as the American Urological Association, American Society for Reproductive Medicine, European Association of Urology, and Brazilian Society of Urology. ${ }^{67-69}$ Thus, surgical correction of the varicocele would only be offered when adolescents have already crossed into the infertile range, even though initial evaluation had already shown that their seminal profiles were significantly lower than their counterparts without varicocele. Due to the progressive nature of varicocele, it is to be expected that treatment of varicocele halts deterioration of sperm quality and prevents individuals with 'normal' semen analysis from crossing into the infertile range. ${ }^{77,78}$ Moreover, improvements in sperm quality after varicocele repair may also increase the male reproductive potential even if pre- and post-treatment values are within the newly proposed reference values. Adolescents and adults with palpable varicoceles may present with a normal semen analysis, but elevated DNA fragmentation rates and oxidative stress levels show they already have altered sperm function. ${ }^{61}$

Studies have shown that men who achieved a postoperative total motile sperm count greater than 20 million and sperm DNA fragmentation decrease after varicocelectomy were more likely to initiate a pregnancy either spontaneously or via assisted reproductive technology (ART). ${ }^{61,62,79-81}$ Our group has recently demonstrated that the treatment of clinical varicoceles may improve the outcome of ICSI in couples with varicocele-related infertility. ${ }^{52}$ In our study, the chances of live birth were significantly increased by 1.9 -fold, and the chance of miscarriage was reduced by 2.3-fold if the varicocele had been treated before assisted conception. Taken together, this knowledge challenges the current recommendations for varicocele treatment and highlights the importance of a continuous debate.

It is still unclear why fertility potential does not always improve after surgery. The distribution of antioxidant enzyme genes in infertile men with varicocele has recently been determined. Studies have suggested that genetic polymorphisms in the glutathione S-transferase T1 gene may affect individual responses to varicocelectomy. ${ }^{96}$ In addition, doctors and researchers have also debated whether varicoceles can cause or contribute to azoospermia. A recent meta-analysis reported the appearance of sperm in the ejaculates of $39 \%$ of azoospermic individuals whose varicoceles had been treated. ${ }^{12}$ In addition, testicular histopathology results were predictive of success. Moreover, the postoperative appearance of sperm in the ejaculates increased 9.4-fold in patients with biopsy-proven HS or MA compared with SCO syndrome. Although the use of motile ejaculated sperm is preferred for $\mathrm{ICSI}^{82}$, persistent azoospermia after varicocele repair is still a potential problem, and sperm extraction before ICSI will be inevitable for many individuals. In the case of persistent azoospermia after varicocelectomy, successful sperm retrieval rates of $60 \%$ have been reported using micro-TESE sperm extraction. ${ }^{83}$ Interestingly, one study suggested that varicocele repair may maximize the chances of retrieving sperm for ICSI in azoospermic men with clinical varicoceles. ${ }^{84}$

\section{Reconstructive Surgery of the Vas Deferens and Epididymis}

Overall patency and pregnancy rates have been shown to be $92 \%$ and $55 \%$, respectively, following microsurgical VV and $78 \%$ and $40 \%$, respectively, following VE (Table 2). ${ }^{19,24,27,34,35,85-89}$ Most pregnancies occur within 24 months after surgery. Pregnancy rates are related to the time elapsed between vasectomy and reversal and to female age. Although the female partner's age does not seem to affect patency rates after vasectomy reversal $(86-90 \%$ in female partners under the age of 40 years old versus $83 \%$ in those over the age of 40 years), it does affect pregnancy rates $(14 \%$ in women over 40 years of age $v s .56 \%$ in those under 39 years of age). ${ }^{90}$ Pregnancy rates are also lower after a longer duration of vasal obstruction. Approximately $30-40 \%$ of couples achieve pregnancy following surgical reconstructions performed after obstruction intervals greater than 15 years; however, more than $50 \%$ achieve pregnancy after shorter intervals. ${ }^{34,91}$ Vasectomy reversal has also been shown to be feasible in patients who failed PESA. Marmar et al. showed that PESA procedures cause limited trauma to the epididymis, and pregnancy rates as high as 50\% may be 
Table 2 - Treatment Results for Vasovasostomy and Vasoepididymostomy. Type of Anastomosis, Patency, and Spontaneous Pregnancy Rates using Various Techniques.

\begin{tabular}{|c|c|c|c|c|}
\hline Author & Patients (n) & Technique & Patency Rate (\%) & Pregnancy Rate (\%) \\
\hline \multicolumn{5}{|l|}{ Vasovasostomy } \\
\hline \multirow[t]{2}{*}{ Belker et al. ${ }^{19}$} & 1,247 & Modified one-layer & 89 & 57 \\
\hline & & Two-layer & 86 & 51 \\
\hline Boorjian \& Lipkin ${ }^{24}$ & 159 & Two-layer & 95 & 83 \\
\hline Chan \& Goldstein ${ }^{85}$ & 1,048 & Two-layer & 99 & 54 \\
\hline Kolettis et al. ${ }^{86}$ & 34 & Both & 76 & 35 \\
\hline \multicolumn{5}{|l|}{ Vasoepididymostomy } \\
\hline Silber ${ }^{34}$ & 139 & End-to-end & 78 & 56 \\
\hline Thomas $^{35}$ & 137 & End-to-side & 79 & 50 \\
\hline Berger ${ }^{87}$ & 12 & Triangulation intussusception & 92 & NR \\
\hline Marmar ${ }^{88}$ & 9 & Modified intussusception & 78 & 22 \\
\hline Chan et al. ${ }^{89}$ & 68 & Triangulation intussusception & 84 & 40 \\
\hline \multirow[t]{4}{*}{ Schiff et al. ${ }^{27}$} & 153 & End-to-end & 73 & NR \\
\hline & & End-to-side & 74 & \\
\hline & & three-suture intussusception & 84 & \\
\hline & & two-suture intussusception & 80 & \\
\hline
\end{tabular}

NR $=$ not reported

obtained in vasectomy reversal after PESA; however, success is higher for couples whose female partners are 37 years old or younger. ${ }^{92}$ Because patency and pregnancy rates of the existing surgical procedures do not reach $100 \%$ and are technically demanding, efforts continue to be made to widen the options for reconstructive repair. Several modifications have been suggested, such as intussusception VE anastomotic techniques, the use of novel biomaterials/sealants, absorbable and nonabsorbable stents, and the use of robotics. ${ }^{32,34,89,93-97}$ Recent modifications to the conventional VE techniques simplified and fastened the anastomoses. In a prospective study, Chan et al. reported overall patency and pregnancy rates of $84 \%$ and $40 \%$, respectively, using an intussusception technique. ${ }^{93}$ These findings were confirmed by Schiff et al., who reported patency and pregnancy rates of approximately $82 \%$ and $45 \%$, respectively, using simplified intussusception techniques. ${ }^{32}$ Interestingly, these studies have also suggested that anastomoses are more water-tight after the use of intussusception techniques, which decreases granuloma formation. Because pregnancy rates following VE are below $50 \%$ and late failures occur in approximately $20 \%$ of the cases, it may be useful to retrieve sperm intraoperatively for cryopreservation, particularly in cases that involve difficult reconstruction.

Sealants are used around the anastomotic site to decrease the operative time and to simplify the procedure without compromising success rates. Fibrin sealant can stimulate the coagulation cascade and produce a fibrin seal around the anastomosis. When mixed with thrombin and calcium, fibrinogen is converted to fibrin monomer, which is converted to a stable cross-linked fibrin polymer. ${ }^{94}$ Ho et al. achieved $85 \%$ patency rates and $23 \%$ pregnancy rates in a mean follow-up time of 6.2 months by using three transmural sutures and fibrin glue. ${ }^{94}$ There are concerns, however, about the potential contact of the glue with the vas lumen, which may result in obstruction. In addition, there are concerns about the transmission of viral disease because fibrin glue is derived from pooled plasma. ${ }^{93}$ The use of nonabsorbable polymeric stents has only been reported in animal models, but the results have been promising. ${ }^{95}$ The use of robotics for microsurgical procedures is also a novel concept. The rationale behind the addition of robotic technology to the already existing armamentarium relies on the possibility of enhancing physiologic static tremor correction, visual magnification (up to $100 \mathrm{X}$ when using a digital microscopic camera), and ergonomics. ${ }^{96}$ Animal studies have suggested that robotic-assisted vasectomy reversals are easier to perform and yield better pregnancy rates than microsurgical reversal. ${ }^{32}$ In a preliminary experience in humans, Parekattil et al. reported shorter operative time and higher postoperative sperm counts with robot-assisted vasectomy reversal compared with microsurgical techniques. ${ }^{94}$ The advantages of a robot over an experienced microsurgeon, however, are yet to be proven in larger series. A robotic system costs more than 1 million dollars and its annual maintenance surpasses one hundred thousand dollars. These cost issues will certainly represent a barrier to the wide adoption of robotics in microsurgical urologic practices.

\section{Transurethral Resection of Ejaculatory Ducts}

Ejaculatory duct obstruction is a treatable cause of male infertility, but it is difficult to diagnose, particularly in cases of partial obstruction. Transrectal ultrasound is valuable, but not specific. Indeed, studies have suggested that adjunctive procedures, such as magnetic resonance imaging, chromotubation, seminal vesicle aspiration, seminal vesicle scintigraphy, and ejaculatory duct manometry are more sensitive for diagnosis. ${ }^{98-100}$ Transurethral resection of ejaculatory ducts remains the treatment of choice, but less invasive approaches using balloon dilation with or without transurethral incision of the ejaculatory ducts has been proposed with similar results and fewer complications than TURED. ${ }^{101,102}$

\section{Sperm Retrieval Techniques}

Currently, there is not a consensus about the best techniques for sperm retrieval in men with OA and NOA. To date, no randomized controlled trial has compared the efficiency of the various strategies; thus, current recommendations are based on cumulative evidence provided by descriptive, observational, and few controlled studies. ${ }^{103}$ For example, PESA can be performed without surgical scrotal exploration, it is easily repeatable at a low cost, does not require an operating microscope or expertise in microsurgery, can be performed under local anesthesia, 
and is associated with minimal postoperative discomfort. Microsurgical aspiration has the advantage of retrieving a larger number of sperm, which facilitates cryopreservation, and it is associated with a reduced risk of hematoma. ${ }^{104}$ Meta-analysis results have not demonstrated any significant differences in any outcome measures between the use of epididymal or testicular sperm in men with OA. ${ }^{105}$ The etiology of the obstruction and the use of fresh or frozenthawed epididymal/testicular sperm do not seem to affect ICSI outcomes in terms of fertilization, pregnancy, or miscarriage rates. ${ }^{104,106,107}$ In our series of 142 men with $\mathrm{OA}$, the cumulative successful retrieval rate of PESA and/or TESA was $97.9 \%$, and an adequate number of motile sperm for cryopreservation were obtained in approximately one third of the cases. ${ }^{104}$ Motile spermatozoa were obtained in approximately $73 \%$ of the cases after the first or second PESA aspirations, and TESA was carried out as a rescue procedure after failed PESA in about $14 \%$ of the individuals. In our series, success in sperm retrieval using percutaneous techniques and pregnancy outcomes by ICSI were similar in the vasectomy, CAVD, and postinfectious etiology categories. ${ }^{106}$ Either epididymal or testicular spermatozoa retrieved from these men exhibited similar reproductive potential, and overall live birth rates were $40.2 \%$. In addition, our data indicated that ICSI outcomes using fresh epididymal and testicular spermatozoa retrieved from men with OA were comparable to those obtained with ejaculated sperm. ${ }^{82}$

In cases of NOA, the efficiency of TESA was lower than TESE, ${ }^{108-110}$ except in the favorable cases of men with previously successful TESA or testicular histopathology showing HS. In these circumstances, sperm retrieval rates (SRR) may be as high as $100 \%{ }^{106}$ In a recent systematic review the mean reported SRR for TESE was $49.5 \% .{ }^{109}$ TESE with multiple biopsies resulted in a higher SRR than fineneedle aspiration, a variation of TESA, especially in cases of SCO syndrome and MA. ${ }^{109}$ In NOA, current evidence suggests that micro-TESE performs better than conventional TESE or TESA in cases of SCO, where tubules containing active foci of spermatogenesis can be positively identified using microsurgery. Sperm retrieval rates ranging from 35$77 \%$ have been reported with micro-TESE. ${ }^{4,32,111-113}$ To allow for adequate healing and the resumption of spermatogenesis, the minimum recommended interval between sperm retrieval procedures in NOA is 3-6 months. ${ }^{97,112,113}$ According to our results involving approximately 200 individuals with NOA, the SRR was $55.7 \%$, and sperm could be obtained in similar rates in multiple etiological categories, including cryptorchidism, orchitis, genetic, radio-/chemotherapy, and idiopathic causes. Testicular histopathology results were predictive of sperm collection using both TESA and micro-TESE. ${ }^{49,52}$ In our group of NOA men presenting with either HS or a history of previous successful TESA attempt, SRR by TESA was $100 \%$ and $82.3 \%$, respectively. Using micro-TESE, SRR were significantly higher than TESA in cases of SCO and MA $(39.2 \%$ vs. $22.8 \%) .{ }^{52}$ Both methods yielded an SRR of $100 \%$ in cases of HS. According to our data, the chances of retrieving spermatozoa (odds ratio $[\mathrm{OR}]=43.0 ; 95 \%$ confidence interval [CI]: 10.3-179.5) and of achieving a live birth by ICSI $(\mathrm{OR}=1.86$; 95\% CI: 1.03-2.89) were significantly increased in couples whose male partner had OA rather than NOA. ${ }^{114}$ These findings indicated that the reproductive potential of infertile men undergoing ART is related to the type of azoospermia (i.e., obstructive or nonobstructive).

Postoperative complications of sperm retrieval techniques include persistent pain, swelling, infection, hydrocele and hematoma. ${ }^{111-113,115,116}$ The development of an intratesticular hematoma has been observed in most patients undergoing TESE with single or multiple biopsies based on ultrasounds results performed after surgery, but the hematomas often resolve spontaneously without compromising testicular function. ${ }^{113}$ In a larger-volume standard testicular biopsy, the risk of transient or even permanent testicular damage (e.g., complete devascularization) can result in decreased serum testosterone levels. ${ }^{110,112}$ Less invasive techniques, such as TESA and micro-TESE, aim to reduce the incidence of complications and long-term consequences of these surgical approaches. Several studies have documented a lower incidence of complications following micro-TESE compared with conventional techniques. ${ }^{109,110,112,115}$ Using micro-TESE, proper identification of testicular vessels under the tunica albuginea is made prior to the placement of an incision into the testis. Optical magnification and microsurgery techniques allow for the preservation of intratesticular blood supply and the identification of tubules that are more likely to harbor sperm production. ${ }^{112}$ Therefore, the efficacy of sperm retrieval is improved, and the risks of large tissue removal are minimized. The small amount of tissue extracted also facilitates sperm processing. ${ }^{111}$ For certain groups of patients (e.g., patients with Klinefelter syndrome), however, who already have diminished androgen production, a temporary decrease in serum testosterone has been documented following micro-TESE. ${ }^{111}$

The pregnancy rates of ICSI using testicular sperm extracted by TESA or micro-TESE in NOA are significantly lower than those obtained with either ejaculated or epididymal/testicular sperm from men with OA. ${ }^{82,105,114}$ Testicular spermatozoa of men with severely impaired spermatogenesis have decreased fertility potential and may have a higher tendency to carry deficiencies (e.g., related to the centrioles and genetic material), which ultimately affect the capability of the male gamete to activate the egg and trigger the formation and development of a normal zygote and a viable embryo. ${ }^{116}$ Although there is limited available data, studies have suggested that the sperm retrieval technique itself has no impact on ICSI success rates. ${ }^{109}$ Nonetheless, frozen-thawed surgicallyretrieved sperm from NOA men have significantly impaired reproductive potential compared with fresh sperm. ${ }^{114,116}$ Meta-analysis results have shown that fertilization rates by ICSI remain similar, but implantation was significantly higher (by 73\%) with the use of fresh compared with frozenthawed testicular sperm. ${ }^{114}$ The question of whether ICSI using sperm retrieved from men with either OA or NOA might be associated with an increased risk of birth defects is still unresolved. In general, IVF techniques are associated with multiple gestation and an increased risk of congenital abnormalities (including hypospadias). ${ }^{117}$ ICSI in particular carries an increased risk of endocrine abnormalities and epigenetic imprinting effects. ${ }^{117}$ Although the absolute risk of any of these conditions remains low, ${ }^{17-120}$ current data is limited, and study populations are heterogenic. Therefore, well-defined groups of ICSI with ejaculated sperm, ICSI with epididymal sperm, ICSI with testicular sperm, and a 
control group of naturally conceived children should be closely monitored.

\section{What is the best treatment option for azoospermic males in the ICSI era?}

Both microsurgical reconstruction and sperm retrieval combined with IVF/ICSI can be effective treatments for infertility due to obstructive azoospermia. A choice between the two must be based not only on the needs and preferences of the individual couple but also on the couple's clinical profile (i.e., taking into account the cause of azoospermia and any coexisting factors in the female partner). Consequently, both partners should be evaluated thoroughly before making a specific treatment recommendation. Cost issues also play a role in the decision-making process because ART is seldom reimbursed by health insurance companies in most countries. Most importantly, infertility clinics and doctors should not limit a couple's options for treatment based on their own technical limitations (i.e., they should always provide all treatment options available for the particular case scenario). According to the most recent data, microsurgical reconstruction of the vas (when performed by an experienced microsurgeon) remains a cost-effective and reliable means of restoring fertility in the majority of men who have previously undergone vasectomy. ${ }^{104,121-124}$ Data comparing surgical reconstruction versus sperm retrieval/ICSI, however, are not randomized or homogenous. Therefore, a comprehensive understanding of the factors that can affect outcomes, overall cost, and the morbidity associated with each treatment modality is recommended.

\section{FINAL CONSIDERATIONS}

Varicocele treatment based on the presence of clinically palpable varicocele and abnormal semen parameters should be reconsidered in light of the newly proposed WHO reference values for laboratory semen analysis. Open microsurgical inguinal or subinguinal techniques are currently the best treatment modalities because they result in higher spontaneous pregnancy rates and fewer recurrences and postoperative complications than laparoscopic, radiologic embolization and macroscopic inguinal or retroperitoneal varicocelectomy techniques. There are no absolute predictive factors for successful varicocele repair, and existing evidence does not support the treatment of infertile men with subclinical varicocele. Surgical repair of varicocele improves semen parameters and functional markers of oxidative stress and DNA integrity. The chance for either spontaneous or assisted conception is increased after the repair of clinical varicocele. In addition, recovery of spermatogenesis can be achieved after the repair of clinical varicocele in infertile men with NOA. Testicular histopathology is predictive of success, and men with MA and HS are more likely to ejaculate motile spermatozoa after surgery. Furthermore, the chance of retrieving testicular sperm for ICSI is optimized in nonobstructed azoospermic men with treated clinical varicocele.

Men with OA may father children either by surgical correction of the obstruction, which may allow the couple to conceive naturally, or retrieval of sperm directly from the epididymis or testis, which is followed by ICSI. The return of sperm to ejaculate after microsurgical reconstructions is achieved in $70-95 \%$ of cases, and $30-75 \%$ of couples achieve unassisted pregnancy. Patency and pregnancy after microsurgical vasectomy reversal are inversely related to the interval of obstruction since the vasectomy. Other factors that affect success rates include the intraoperative appearance of vasal fluid, the presence or absence of sperm in the vasal fluid (and their quality), the length of the remaining segment adjacent to the epididymis, the age of the female partner, and the experience of the surgeon.

TURED is the treatment of choice for EDO. After TURED, sperm return to the ejaculate in approximately $50-75 \%$ of men, and approximately $20 \%$ of couples achieve pregnancy; however, results depend on the etiology (acquired or congenital) and type (partial or complete) of obstruction. Complications of TURED, which include hematuria, hematospermia, urinary tract infection, epididymitis, and a watery ejaculate due to a reflux of urine, occur in approximately $20 \%$ of men.

In OA, sperm production is normal and gametes can be easily retrieved from the epididymides or testicles in approximately $100 \%$ of cases, irrespective of the technique. In NOA, successful sperm retrieval is approximately $50 \%$. The use of microsurgery during TESE may improve the efficacy of sperm extraction with significantly less tissue removed, which ultimately facilitates sperm processing. Testicular histology results, if available, may be useful to predict the chances of retrieving sperm in men with NOA. Interestingly, sperm can be obtained in almost all scenarios except cases of Y chromosome infertility with complete AZFa and/or AZFb microdeletions. In both OA and NOA, the sperm retrieval technique itself does not seem to impact IVF/ICSI success rates. Nonetheless, the chances of retrieving spermatozoa and of achieving a live birth by ICSI are increased in couples whose male partner had OA rather than NOA. Children conceived using sperm retrieved from men with OA or NOA should be monitored because it is still unclear if there is an increased risk of birth defects when ICSI is carried out with nonejaculated sperm.

\section{REFERENCES}

1. Vital and Health Statistics, series 23, no. 26, CDC. http:/ /www.cdc.gov. Acessed December 10, 2009.

2. Silber SJ, Nagy ZP, Liu J, Godoy H, Devroey P, Van Steirteghem AC. Conventional in-vitro fertilization versus intracytoplasmic sperm injection for patients requiring microsurgical sperm aspiration. Hum Reprod. 1994;9:1705-9.

3. Devroey P, Liu J, Nagy Z, Goossens A, Tournaye H, Camus M, et al. Pregnancies after testicular extraction (TESE) and intracytoplasmic sperm injection (ICSI) in non-obstructive azoospermia. Hum Reprod. 1995;10:1457-60.

4. Schlegel PN. Testicular sperm extraction: microdissection improves sperm yield with minimal tissue excision. Hum Reprod. 1999;14:131-5, doi: 10.1093/humrep/14.1.131.

5. Esteves S. Infertilidade masculina. In: Rhoden EL, Ed. Urologia no consultório, $1^{\text {a }}$. ed Porto Alegre, RS: Artmed Editora; 2009:470-500.

6. Libman J, Jarvi K, Lo K, Zini A. Beneficial effect of microsurgical varicocelectomy is superior for men with bilateral versus unilateral repair. J Urol. 2006;176:2602-5, doi: 10.1016/j.juro.2006.07.161.

7. Gat Y, Bachar GN, Zukerman Z, Belenky A, Gorenish M. Physical examination may miss the diagnosis of bilateral varicocele: a comparative study of 4 diagnostic modalities. J Urol. 2004;172:1414-7, doi: 10. 1097/01.ju.0000138540.57137.5f.

8. Geatti O, Gasparini D, Shapiro B. A comparison of scintigraphy, thermography, ultrasound and phlebography in grading of clinical varicocele. J Nucl Med. 1991;32:2092-7.

9. Yamamoto M, Hibi H, Hirata Y, Miyake K, Ishigaki T. Effect of varicocelectomy on sperm parameters and pregnancy rate in patients with subclinical varicocele: a randomized prospective controlled study. J Urol. 1996;155:1636-8, doi: 10.1016/S0022-5347(01)66149-4.

10. Kantartzi PD, Goulis ChD, Goulis GD, Papadimas I. Male infertility and varicocele: myths and reality. Hippokratia. 2007;11:99-104.

11. Esteves SC, Glina S. Recovery of spermatogenesis after microsurgical subinguinal varicocele repair in azoospermic men based on testicular 
histology. Int Braz J Urol. 2005;31:541-8, doi: 10.1590/S167755382005000600005.

12. Weedin JW, Khera M, Lipshultz LI. Varicocele Repair in Patients with Nonobstructive Azoospermia - A Meta-Analysis. J Urol. 2010;183:230915, doi: 10.1016/j.juro.2010.02.012.

13. Esteves SC. Editorial comment. J Urol. 2010;183:2315, doi: 10.1016/j. juro.2010.02.2419.

14. Cayan S, Shavakhabov S, Kadioglu A. Treatment of palpable varicocele review in infertile men: a meta-analysis to define the best technique. J Androl. 2009;30:33-40, doi: 10.2164/jandrol.108.005967.

15. Sautter T, Sulser T, Suter S, Gretener H, Hauri D. Treatment of varicocele: a prospective randomized comparison of laparoscopy versus antegrade sclerotherapy. Eur Urol. 2002;41:398-400, doi: 10. 1016/S0302-2838(02)00022-2.

16. Al-Kandari AM, Shabaan H, Ibrahim HM, Elshebiny YH, Shokeir AA. Comparison of outcomes of different varicocelectomy techniques: open inguinal, laparoscopic, and subinguinal microscopic varicocelectomy: a randomized clinical trial. Urology. 2007;69:417-20, doi: 10.1016/j. urology.2007.01.057

17. Hopps CV, Lemer ML, Schlegel PN, Goldstein M. Intraoperative varicocele anatomy: a microscopic study of the inguinal versus subinguinal approach. J Urol. 2003;170:2366-70, doi: 10.1097/01.ju. 0000097400.67715.f8.

18. Esteves SC, Oliveira FV, Bertolla RP. Clinical outcomes of intracytoplasmic sperm injection in infertile men with treated and untreated clinical varicocele. J Urol. 2010; 184:1442-6, doi: 10.1016/j.juro.2010.06. 004.

19. Belker AM, Thomas AJ Jr, Fuchs EF, Konnak JW, Sharlip ID. Results of 1469 microsurgical vasectomy reversals by the Vasovasostomy Study Group. J Urol. 1991;145:505-11.

20. Vasectomia no Brasil. Veja online; http://veja.abril.com.br/041000/ p_084.html. Accessed October 3rd, 2010.

21. Lipshultz LI, Rumohr JA, Bennet RC. Techniques for Vasectomy Reversal. Urol Clin N Am. 2009;36:375-82, doi: 10.1016/j.ucl.2009.05. 011.

22. Parekattil SJ, Kuang W, Agarwal A, Thomas AJ. Model to predict if a vasoepididymostomy will be required for vasectomy reversal. J Urol. 2005;173:1681-4, doi: 10.1097/01.ju.0000154608.08496.f2.

23. Hernandez J, Sabanegh ES. Repeat vasectomy reversal after initial failure. J Urol. 1999;161:1153-6, doi: 10.1016/S0022-5347(01)61616-1.

24. Boorjian S, Lipkin M, Goldstein M. The impact of obstructive interval and sperm granuloma on outcome of vasectomy reversal. J Urol. 2004;171:304-6, doi: 10.1097/01.ju.0000098652.35575.85.

25. Carbone DJ Jr, Shah A, Thomas AJ Jr, Agarwal A. Partial obstruction, not antisperm antibodies, causing infertility after vasovasostomy. J Urol. 1998;159:827-30, doi: 10.1016/S0022-5347(01)63744-3.

26. Chawla A, O'Brien I, Lisi M, Zini A, Jarvi K. Should all urologists performing vasectomy reversal be able to perform vasoepididymostomy if required? J Urol. 2004;172:1048-50, doi: 10.1097/01.ju. 0000135118.43383.b1

27. Schiff J, Chan P, Li PS, Finkelberg S, Goldstein M. Outcome and late failures compared in 4 techniques of microsurgical vasoepididymostomy in 153 consecutive men. J Urol. 2005;174:651-5, doi: 10.1097/01.ju. 0000165573.53109.92.

28. Sharlip ID. Microsurgical vasovasostomy: Modified One-Layer Technique. In: Goldstein M, ed. Surgery of Male Infertility. $1^{\text {st }}$ ed. New York, NY: WB Saunders Co., 1995:67-76.

29. Belker AM. Microsurgical vasovasostomy: Two-Layer Technique. In: Goldstein M, ed. Surgery of Male Infertility. $1^{\text {st }}$ ed. New York, NY: WB Saunders Co, 1995:61-76.

30. Goldstein M. Vasovasostomy: Surgical Approach, Decision Making, and Multilayer Microdot Technique. In: Goldstein M, ed. Surgery of Male Infertility. $1^{\text {st }}$ ed. New York, NY: WB Saunders Co, 1995:46-60.

31. Fleming C. Robot-assisted vasovasostomy. Urol Clin N Am. 2004;31:769-772, doi: 10.1016/j.ucl.2004.07.001.

32. Parekattil SJ, Cohen MS. Robotic surgery in male infertility and chronic orchialgia. Curr Opin Urol. 2010;20:75-79, doi: 10.1097/MOU. 0b013e3283337aa0.

33. Boyle KE, Thomas AJ Jr, Marmar JL, Hirshberg S, Belker AM, Jarow JP. Sperm harvesting and cryopreservation during vasectomy reversal is not cost effective. Fertil Steril. 2006;85:961-4, doi: 10.1016/j.fertnstert. 2005.09.031.

34. Silber S. Microscopic vasoepididymostomy: specific microanastomosis to the epididymal tubule. Fertil Steril.1978;30:565-71

35. Thomas AJ Jr. Vasoepididymostomy. Urol Clin North Am.1987;14:52738.

36. Jee SH, Hong YK. One-layer vasovasostomy: microsurgical versus loupe-assisted. Fertil Steril. 2010;94:2308-11, doi: 10.1016/j.fertnstert. 2009.12.013.

37. Netto NR Jr, Esteves SC, Neves PA. Transurethral resection of partially obstructed ejaculatory ducts: seminal parameters and pregnancy outcomes according to the etiology of obstruction. J Urol. 1998;159:2048-53, doi: 10.1016/S0022-5347(01)63243-9.
38. Meacham RB, Hellerstein DK, Lipshultz LI. Evaluation and treatment of ejaculatory duct obstruction in the infertile male. Fertil Steril. 1993;59: 393-7.

39. Carter SS, Shinohara K, Lipshultz LI. Transrectal ultrasonography in disorders of the seminal vesicles and ejaculatory ducts. Urol Clin N Am. 1989;16:773-90.

40. Hellerstein DK, Meacham RB, Lipshultz LI. Transrectal ultrasound and partial ejaculatory duct obstruction in male infertility. Urology. 1992;39:449-52, doi: 10.1016/0090-4295(92)90245-R.

41. Jones TR, Zagoria RJ, Jarow JP. Transrectal US-guided seminal vesiculography. Radiology. 1997;205:276-8.

42. Jarow JP, Espeland MA, Lipshultz LI. Evaluation of the azoospermic patient. J Urol. 1989;142:62-5.

43. Farley S, Barnes R. Stenosis of ejaculatory ducts treated by endoscopic resection. J Urol. 1973;109:664-6.

44. Craft I, Tsirigotis M, Bennett V, Taranissi M, Khalifa Y, Hogewind G, et al. Percutaneous epididymal sperm aspiration and intracytoplasmic sperm injection in the management of infertility due to obstructive azoospermia. Fertil Steril. 1995;63:1038-42.

45. Craft I, Tsirigotis M. Simplified recovery, preparation and cryopreservation of testicular spermatozoa. Hum Reprod. 1995;10:1623-7.

46. Okada H, Dobashi M, Yamazaki T, Hara I, Fujisawa M, Arakawa S, et al. Conventional versus microdissection testicular sperm extraction for nonobstructive azoospermia. J Urol. 2002;168:1063-7, doi: 10.1016/ S0022-5347(05)64575-2.

47. Tsujimura A, Matsumiya K, Miyagawa $\mathrm{Y}$, Tohda A, Miura H, Nishimura K, Koga M, et al. Conventional multiple or microdissection testicular sperm extraction: a comparative study. Hum Reprod. 2002;17:2924-29, doi: 10.1093/humrep/17.11.2924.

48. Ramasamy R, Lin K, Gosden LV, Rosenwaks Z, Palermo GD, Schlegel $\mathrm{PN}$. High serum FSH levels in men with nonobstructive azoospermia does not affect success of microdissection testicular sperm extraction. Fertil Steril. 2009;92:590-3, doi: 10.1016/j.fertnstert.2008.07.1703.

49. Esteves SC, Verza S Jr, Gomes AP. Successful retrieval of testicular spermatozoa by microdissection (micro-TESE) in nonobstructive azoospermia is related to testicular histology. Fertil Steril. 2006;86:S354, doi: 10.1016/j.fertnstert.2006.07.966.

50. Schlegel PN. Causes of azoospermia and their management. Reprod Fertil Dev. 2004;16:561-72, doi: 10.1071/RD03087.

51. Sharlip ID, Jarow J, Belker AM, Damewood M, Howards SS, Lipshultz LI, et al. Report on Evaluation of the Azoospermic Male. AUA Best Practice Policy and ASRM Practice Committee Report. American Urological Association, April 2001.

52. Esteves SC, Verza S, Prudencio C, Seol B. Sperm retrieval rates (SRR) in nonobstructive azoospermia (NOA) are related to testicular histopathology results but not to the etiology of azoospermia. Fertil Steril. 2010;94 (Suppl):S132, doi: 10.1016/j.fertnstert.2010.07.532.

53. Male Infertility Best Practice Policy Committee of the American Urological Association; Practice Committee of the American Society for Reproductive Medicine. Report on evaluation of the azoospermic male. Fertil Steril. 2006;86(Suppl 1):S210-215.

54. De Braekeleer M, Dao TN. Cytogenetic studies in male infertility: a review. Hum Reprod. 1991;6:245-50.

55. Brandell RA, Mielnik A, Liotta D, Ye Z, Veeck LL, Palermo GD, et al $\mathrm{AZFb}$ deletions predict the absence of spermatozoa with testicular sperm extraction: preliminary report of a prognostic genetic test. Hum Reprod. 1998;13:2812-5.

56. Hopps CV, Mielnik A, Goldstein M, Palermo GD, Rosenwaks Z, Schlegel PN. Detection of sperm in men with $Y$ chromosome microdeletions of the AZFa, AZFb and AZFc regions. Hum Reprod. 2003;18:1660-5, doi: 10.1093/humrep/deg348.

57. Cocuzza M, Pagani R, Coelho R, Srougi M, Hallak J. The systematic use of intraoperative vascular Doppler ultrasound during microsurgical subinguinal varicocelectomy improves precise identification and preservation of testicular blood supply. Fertil Steril. 2010;93:2396-9, doi: 10. 1016/j.fertnstert.2009.01.088.

58. Schlesinger MH, Wilets IF, Nagler HM. Treatment outcome after varicocelectomy. A critical analysis. Urol Clin North Am. 1994;21:51729.

59. Shindel AW, Yan Y, Naughton CK. Does the number and size of veins ligated at left-sided microsurgical subinguinal varicocelectomy affect semen analysis outcomes? Urology. 2007;69:1176-80, doi: 10.1016/j. urology.2007.01.086.

60. Colpi GM, Carmignani L, Nerva F, Piediferro G, Castiglioni F, Grugnetti C, et al. Surgical treatment of varicocele by a subinguinal approach combined with antegrade intraoperative sclerotherapy of venous vessels. BJU Int. 2006;97:142-5, doi: 10.1111/j.1464-410X.2006. 05915.x.

61. Zini A, Blumenfeld A, Libman J, Willis J. Beneficial effect of microsurgical varicocelectomy on human sperm DNA integrity. Hum Reprod. 2005;20:1018-21, doi: 10.1093/humrep/deh701.

62. Moskovtsev SI, Lecker I, Mullen JB, Jarvi K, Willis J, White J, et al Cause-specific treatment in patients with high sperm DNA damage 
resulted in significant DNA improvement. Syst Biol Reprod Med. 2009:55:109-15, doi: 10.1080/19396360902787944.

63. Kondo Y, Ishikawa T, Yamaguchi K, Fujisawa M. Predictors of improved seminal characteristics by varicocele repair. Andrologia. 2009;41:20-3, doi: 10.1111/j.1439-0272.2008.00882.x.

64. Cocuzza M, Cocuzza MA, Bragais FM, Agarwal A. The role of varicocele repair in the new era of assisted reproductive technology. Clinics. 2008;63:395-404, doi: 10.1590/S1807-59322008000300018.

65. Zheng YQ, Gao X, Li ZJ, Yu YL, Zhang ZG, Li W. Efficacy of bilateral and left varicocelectomy in infertile men with left clinical and right subclinical varicoceles: a comparative study. Urology. 2009;73:1236-40, doi: 10.1016/j.urology.2008.11.050.

66. Elbendary MA, Elbadry AM. Right subclinical varicocele: how to manage in infertile patients with clinical left varicocele? Fertil Steril. 2009:92:2050-3, doi: 10.1016/j.fertnstert.2009.05.069.

67. The Male Infertility Best Practice Policy Committee of the American Urological Association; Practice Committee of the American Society for Reproductive Medicine. Report on varicocele and infertility. Fertil Steril 2004;82:S142-5.

68. European Association of Urology. Guidelines on Male Infertility; 2010; Available from: http://www.uroweb.org/gls/pdf/Male\%20Infertility\% 202010.pdf (cited: February $27^{\text {th }}, 2011$ ).

69. Sociedade Brasileira de Urologia \& Colégio Brasileiro de Radiologia; Projeto Diretrizes da Associação Médica Brasileira. Varicocele. Available from: http://www.projetodiretrizes.org.br/8_volume/40Varicocele.pdf (cited: February $27^{\text {th }}, 2011$ ).

70. Marmar JL, Agarwal A, Prabakaran S, Agarwal R, Short RA, Benoff S, et al. Reassessing the value of varicocelectomy as a treatment for male subfertility with a new meta-analysis. Fertil Steril. 2007;88:639-48, doi: 10.1016/j.fertnstert.2006.12.008.

71. World Health Organization. WHO Laboratory Manual for the Examination of Human Semen and Sperm-cervical Mucus Interaction, $2^{\text {nd }}$ ed. Cambridge: Cambridge University Press 1987;80p.

72. World Health Organization. WHO Laboratory Manual for the Examination of Human Semen and Sperm-cervical Mucus Interaction, $3^{\text {rd }}$ ed. Cambridge: Cambridge University Press 1992;107p.

73. World Health Organization. WHO Laboratory Manual for the Examination of Human Semen and Sperm-cervical Mucus Interaction, $4^{\text {th }}$ ed. Cambridge: Cambridge University Press 1999;128p.

74. World Health Organization. WHO Laboratory Manual for the Examination and Processing of Human Semen, $5^{\text {th }}$ ed. Geneva: WHO press, 2010, 287p.

75. Agarwal A, Deepinder F, Cocuzza M, Agarwal R, Short RA, Sabanegh E, et al. Efficacy of Varicocelectomy in Improving Semen Parameters: New Meta-analytical Approach. Urology. 2007;70:532-8.

76. Mori MM, Bertolla RP, Fraietta R, Ortiz V, Cedenho AP. Does varicocele grade determine extent of alteration to spermatogenesis in adolescents? Fertil Steril. 2008;90:1769-73, doi: 10.1016/j.fertnstert.2007.09.052.

77. Gorelick JI, Goldstein M. Loss of fertility in men with varicocele. Fertil Steril 1993;59:613-6.

78. Witt MA, Lipshultz LI. Varicocele: a progressive or static lesion? Urology. 1993;42:541-3, doi: 10.1016/0090-4295(93)90268-F.

79. Matkov TG, Zenni M, Sandlow J, Levine LA. Preoperative semen analysis as a predictor of seminal improvement following varicocelectomy. Fertil Steril. 2001;75:63-68, doi: 10.1016/S0015-0282(00)01644-7.

80. Smit M, Romijn JC, Wildhagen MF, Veldhoven JL, Weber RF, Dohle GR. Decreased sperm DNA fragmentation after surgical varicocelectomy is associated with increased pregnancy rate. J Urol. 2010;183:270-4, doi: 10. 1016/j.juro.2009.08.161

81. Jeng SY, Wu SM, Lee JD. Cadmium accumulation and metallothionein overexpression in internal spermatic vein of patients with varicocele. Urology. 2009;73:1231-5, doi: 10.1016/j.urology.2009.01.008.

82. Verza S Jr, Esteves SC. Sperm defect severity rather than sperm source is associated with lower fertilization rates after intracytoplasmic sperm injection. Int Braz J Urol. 2008,34:49-56.

83. Schlegel PN, Kaufmann J. Role of varicocelectomy in men with nonobstructive azoospermia. Fertil Steril. 2004;81:1585-8, doi: 10.1016/ j.fertnstert.2003.10.036

84. Inci K, Hascicek M, Kara O, Dikmen AV, Gürgan T, Ergen A. Sperm retrieval and intracytoplasmic sperm injection in men with nonobstructive azoospermia, and treated and untreated varicocele. J Urol. 2009;182:1500-5, doi: 10.1016/j.juro.2009.06.028.

85. Chan PT, Goldstein M. Superior outcomes of microsurgical vasectomy reversal in men with the same female partners. Fertil Steril. 2004; 81:1371-4, doi: 10.1016/j.fertnstert.2003.09.066

86. Kolletis PN, Burns JR, Nangia AK, et al. Outcomes for vasovasostomy performed when only sperm parts are present in the vasal fluid. J Androl. 2006;27:565-7, doi: 10.2164/jandrol.05190.

87. Berger RE. Triangulation end-to-side vasoepididymostomy. J Urol. 1998;159:1951-3, doi: 10.1016/S0022-5347(01)63205-1.

88. Marmar JL. Modified vasoepididymostomy with simultaneous double needle placement, tubulotomy and tubular invagination. J Urol. 2000;163:483-6, doi: 10.1016/S0022-5347(05)67907-4.
89. Chan PT, Brandell RA, Goldstein M. Prospective analysis of outcomes after microsurgical intussusceptions vasoepididymostomy. BJU Int. 2005;96:598-601, doi: 10.1111/j.1464-410X.2005.05691.x.

90. Gerrard ER Jr, Sandlow JI, Oster RA, Burns JR, Box LC, Kolettis PN. Effect of female partner age on pregnancy rates after vasectomy reversal. Fertil Steril. 2007;87:1340-4, doi: 10.1016/j.fertnstert.2006.11. 038

91. Bolduc S, Fischer MA, Deceuninck G, Thabet M. Factors predicting overall success: a review of 74 microsurgical vasovasostomies. Can Urol Assoc J. 2007;1:388-91.

92. Marmar JL, Sharlip I, Goldstein M. Results of vasovasostomy or vasoepididymostomy after failed percutaneous epididymal sperm aspirations. J Urol. 2008;179:1506-9, doi: 10.1016/j.juro.2007.11.050.

93. Kolettis PN. Restructuring Reconstructive Techniques - Advances in Reconstructive Techniques. Urol Clin N Am. 2008;35:229-34, doi: 10. 1016/j.ucl.2008.01.016

94. Ho KL, Witte MN, Bird ET, Hakim S. Fibrin glue assisted 3-suture vasovasostomy. J Urol. 2005;174:1360-3, doi: 10.1097/01.ju.0000173941. 87775.35 .

95. Vrijhof EJ, De Bruine A, Zwinderman AH, Lycklama à Nijeholt AA, Koole LH. The use of newly designed nonabsorbable polymeric stent in reconstructing the vas deferens: a feasibility study in New Zealand white rabbits. BJU Int. 2005:95:1081-5, doi: 10.1111/j.1464-410X.2005. 05471.x.

96. Parekattil SJ, Atalah HN, Cohen MS. Video technique for human robotassisted microsurgical vasovasostomy. J Endourol. 2010;24:511-4, doi: 10.1089/end.2009.0235

97. Schiff J, Li PS, Goldstein M. Robotic microsurgical vasovasostomy and vasoepididymostomy in rats. Int J Med Robot. 2005;1:122-126.

98. Eisenberg ML, Walsh TJ, Garcia MM, Shinohara K, Turek PJ. Ejaculatory duct manometry in normal men and in patients with ejaculatory duct obstruction. J Urol. 2008;180:255-60, doi: 10.1016/j.juro. 2008.03.019.

99. Orhan I, Duksal I, Onur R, Balci TA, Poyraz K, Firdolas F, et al. Technetium Tc $99 \mathrm{~m}$ sulphur colloid seminal vesicle scintigraphy: a novel approach for the diagnosis of the ejaculatory duct obstruction. Urology. 2008;71:672-6, doi: 10.1016/j.urology.2007.11.103.

100. Onur MR, Orhan I, Firdolas F, Onur R, Kocakoç E. Clinical and radiological evaluation of ejaculatory duct obstruction. Arch Androl. 2007;53:179-86, doi: 10.1080/01485010701426448.

101. Lawler LP, Cosin O, Jarow JP, Kim HS. Transrectal US-guided seminal vesiculography and ejaculatory duct recanalization and balloon dilation for treatment of chronic pelvic pain. J Vasc Interv Radiol. 2006;17:16973, doi: 10.1097/01.RVI.0000186956.00155.26.

102. Manohar T, Ganpule A, Desai M. Transrectal ultrasound- and fluoroscopic-assisted transurethral incision of ejaculatory ducts: a problem-solving approach to nonmalignant hematospermia due to ejaculatory duct obstruction. Endourol. 2008;22:1531-5, doi: 10.1089/ end.2007.0415.

103. Van Peperstraten A, Proctor ML, Johnson NP, Philipson G. Techniques for surgical retrieval of sperm prior to ICSI for azoospermia. Cochrane Database Syst Rev. 2006;3:CD002807.

104. Male Infertility Best Practice Policy Committee of the American Urological Association; Practice Committee of the American Society for Reproductive Medicine. Report on the management of infertility due to obstructive azoospermia. Fertil Steril. 2008;90(Suppl. 3):S121-24.

105. Nicopoullos JD, Gilling-Smith C, Almeida PA, Norman-Taylor J, Grace I, Ramsay JW. Use of surgical sperm retrieval in azoospermic men: a meta-analysis. Fertil Steril. 2004;82:691-701, doi: 10.1016/j.fertnstert. 2004.02.116.

106. Esteves SC, Verza S, Prudencio C, Seol B. Success of percutaneous sperm retrieval and intracytoplasmic sperm injection (ICSI) in obstructive azoospermic (OA) men according to the cause of obstruction. Fertil Steril. 2010;94(Suppl):S233, doi: 10.1016/j.fertnstert.2010.07.906.

107. Kamal A, Fahmy I, Mansour R, Serour G, Aboulghar M, Ramos L, et al. Does the outcome of ICSI in cases of obstructive azoospermia depend on the origin of the retrieved spermatozoa or the cause of obstruction? A comparative analysis. Fertil Steril. 2010;94:2135-40, doi: 10.1016/j. fertnstert.2010.01.041.

108. Hauser R, Yogev L, Paz G, Yavetz H, Azem F, Lessing JB, et al. Comparison of efficacy of two techniques for testicular sperm retrieval in nonobstructive azoospermia: multifocal testicular sperm extraction versus multifocal testicular sperm aspiration. J Androl. 2006;27:28-33, doi: 10.2164 /jandrol.05055.

109. Donoso P, Tournaye H, Devroey P. Which is the best sperm retrieval technique for non-obstructive azoospermia? A systematic review. Hum Reprod Update. 2007;13:539-549, doi: 10.1093/humupd/dmm029.

110. Carpi A, Sabanegh E, Mechanick J. Controversies in the management of nonobstructive Azoospermia. Fertil Steril. 2009;91:963-970, doi: 10. 1016/j.fertnstert.2009.01.083.

111. Schiff JD, Palermo GD, Veeck LL, Goldstein M, Rosenwaks Z, Schlegel $\mathrm{PN}$, et al. Success of testicular sperm injection and intracytoplasmic sperm injection in men with Klinefelter syndrome. J Clin Endocrinol Metab. 2005;90:6263-7, doi: 10.1210/jc.2004-2322. 
112. Ramasamy R, Yagan N, Schlegel PN. Structural and functional changes to the testis after conventional versus microdissection testicular sperm extraction. Urology. 2005;65:1190-4, doi: 10.1016/j.urology.2004.12.059.

113. Carpi A, Menchini Fabris FG, Palego P, Di Coscio G, Romani R, Nardini $\mathrm{V}$, et al. Fine-needle and large needle percutaneous aspiration biopsy of the testicle in men with nonobstructive azoospermia: safety and diagnostic performance. Fertil Steril. 2005;83:1029-33, doi: 10.1016/j. fertnstert.2004.09.027.

114. Prudencio C, Seol B, Esteves SC. Reproductive potential of azoospermic men undergoing intracytoplasmic sperm injection is dependent on the type of azoospermia. Fertil Steril. 2010;94(Suppl):S232-S233, doi: 10. 1016/j.fertnstert.2010.07.903.

115. Turunc T, Gul U, Haydardedeoglu B, Bal N, Kuzgunbay B, Peskircioglu $\mathrm{L}$, et al. Conventional testicular sperm extraction combined with the microdissection technique in nonobstructive azoospermic patients: a prospective comparative study. Fertil Steril. 2010;94:2157-60, doi: 10. 1016/j.fertnstert.2010.01.008.

116. TesarikJ: Paternal effects on cell division in the human preimplantation embryo. Reprod Biomed Online. 2005;10:370-5, doi: 10.1016/S14726483(10)61798-1.

117. Alukal JP, Lamb DJ. Intracytoplasmic sperm injection (ICSI)—what are the risks? Urol Clin North Am. 2008;35:277-88, doi: 10.1016/j.ucl.2008. 01.004

118. Knoester M, Helmerhorst FM, Vandenbroucke JP, van der Westerlaken LA, Walther FJ, Veen S, et al. Artificial Reproductive Techniques
Follow-up Project. Cognitive development of singletons born after intracytoplasmic sperm injection compared with in vitro fertilization and natural conception. Fertil Steril. 2008;90:289-96, doi: 10.1016/j. fertnstert.2007.06.090.

119. Belva F, Henriet S, Liebaers I, et al. Medical outcome of 8-year-old singleton ICSI children and a spontaneously conceived comparison group. Hum Reprod. 2007;22:506-15, doi: 10.1093/humrep/del372.

120. Woldringh GH, Besselink DE, Tillema AH, Hendriks JC, Kremer JA. Karyotyping, congenital anomalies and follow-up of children after intracytoplasmic sperm injection with non-ejaculated sperm: a systematic review. Hum Reprod Update. 2010;16:12-9, doi: 10.1093/humupd/ dmp030.

121. Lee R, Li PS, Goldstein M, Tanrikut C, Schattman G, Schlegel PN. A decision analysis of treatments for obstructive azoospermia. Hum Reprod. 2008;23:2043-9, doi: 10.1093/humrep/den200.

122. Robb P, Sandlow JI. Cost-Effectiveness of Vasectomy Reversal. Urol Clin N Am. 2009;36:391-6, doi: 10.1016/j.ucl.2009.05.003.

123. Malizia BA, Hacker MR, Penzias AS. Cumulative live-birth rates after in vitro fertilization. N Engl J Med. 2009;360:236-43, doi: 10.1056/ NEJMoa0803072.

124. Hsieh MH, Meng MV, Turek PJ. Markov modeling of vasectomy reversal and ART for infertility: how do obstructive interval and female partner age influence cost effectiveness? Fertil Steril. 2007;88:840-6, doi: 10.1016/j.fertnstert.2006.11.199. 